\title{
Movies and Series: An Aid for Secondary Language Acquisition
}

\author{
${ }^{1}$ Dhanya A P, ${ }^{2}$ Heera $B,{ }^{3}$ Amrutha $S,{ }^{4} M$ Sreeparvathy, \\ ${ }^{1}$ Research Scholar, Department of English, Amrita Vishwa Vidyapeetham, Amritapuri, India \\ ${ }^{2}$ Research Scholar, Department of English, Amrita Vishwa Vidyapeetham, Amritapuri, India \\ ${ }^{3}$ PG Student, Department of English, Amrita Vishwa Vidyapeetham, Amritapuri, India \\ ${ }^{4}$ PG Student, Department of English, Amrita Vishwa Vidyapeetham, Amritapuri, India
}

\begin{abstract}
English, though an adopted language in colonized countries like India, has deep cultural roots there. Not only has English enriched the languages of these nations but has also lend itself to the medium of creative expression in these countries. It has become part and parcel of intelligence as well as emotional makeup of the educated people there. It is the language required by the world for greater understanding. Today, the compulsions of learning English are no longer nearly political but scientific and technological. Watching videos is always entertaining. Apart from entertainment, video watching is thoroughly a teaching and learning process. Therefore English language acquisition can be made easy with videos as an aid. The research seeks to prove how far videos help in language acquisition and the quantitative research analyses a sample group of children belonging to the age group of 8-10 years.
\end{abstract}

Keywords: visual aid, second language acquisition, technology, quantitative, children

Technology has now become an inseparable part of human beings and it has got the supremacy over the lives of human beings. Technology has not just made the life much easier but has brought a bigger change in the field of education also. The impact that it has created is tremendous and as the young scholars these days are 'digital natives', there will be a keen interest among them for studying if the mode of learning go hand in hade with their interest. Thus the attitude of the typical teaching learning process will get altered and acquiring the knowledge for life will become an attention-grabbing process.

Second language acquisition is a course of action in which a student learns a foreign language other than their primary language. There are different modes of learning the language but there are various benefits or advantages of learning it through the help of videos. Among the youngsters there seems to have an addiction over motion pictures than their text books. What the elders need to do is that, they should identify this interest of the children and have to make it beneficial. Engage them with more videos that can be used as their study material, thereby they can relax and learn simultaneously.

When it comes to second language acquisition many of the Schools and Universities around the globe has adopted the mode of teaching the language through technological means. But, only a few of them give emphasis on this method and precisely speaking about Kerala the rate is very low. This made the authors think about doing a research in this area and to make it clear that this is an authentic language learning device.

Movies or series, be it soap operas or cartoons, has got the influence to grab the concentration of the spectators; moreover the audience will try to concentrate on the dialogues in order to understand what is happening in the scene which in turn will help in improving the concentration skill as well as the vocabulary. It is through these kinds of videos that one will get to understand the pronunciation of words in an authentic way. Another positive aspect of watching video and learning is that it will be present in the memory for a long time as "Videos generate visual stimulants that wake up the brain cells and demand focused attention."(D, 2019 par11). Like every coin has two sides even in this there are negative impacts for this method also. If a video with a boring content is shown to the children they will either sleep or will be busy in their own world therefore it is the responsibility of the teacher to check the video before playing it to the children and see if the video is a likable one for the kids. A talking fish, helpful lions, sleeping princess, fighting machines can make the children stick to their seats.

In the initial stage it is advised to show videos with captions as it will be difficult for the children to distinguish the accent and words in addition this can improve the reading skills of the students. When they become familiar with the tone and pronunciation the captions can be turned off and using this method the grammar, vocabulary and the exact pronunciation can also be learned.

A whole movie or series can help in improving the four communicative skills that is listening, speaking, reading and writing. Once the video is watched by the students the teacher can ask them to give a write up regarding what they watched and also talk about what fascinated them in the video and also about the aspects that they noticed while others didn't. There are historic movies and biographies which take the students to an era that they haven't seen and only heard of. They will get to learn more about the period and the historical aspects. 
There are novels which get 'filmatized' and this can be reached to those audiences who prefer to watch movies than read. Nicholas Sparks, Khaled Hosseini, Shakespear, R.K Narayan, Jane Austen, J.K Rowling are a few names whose works were adapted into movies and series and have got many admirers for the same. For all those who love reading, the videos tend to pique the curiosity and as a result they will grab the book at the earliest opportunity. By this means, they will be able to differentiate between a writer's and a director's point of view. Visual aid is also helpful in introducing the students into the world of aesthetics. They start understanding and appreciating the cultural differences. The movies like Finding Nemo, Ice Age series, Apocalypto, The Pursuit of Happiness are good examples to show kids the importance of team spirit, dedication, hard work and honesty. Resultantly it can be stated that this method of audio-visual learning is a value based education system were not only moral values of students will have a hike but also their command over the language.

\section{Analysis}

The quantitative analysis is based on a survey with the help of questionnaire. The sampling is taken from the age group of 8-10, the students of classes 3, 4 and 5. In the analysis, 100 students from two schools in Trivandrum, Kerala were taken. The students are subjected to a video of 15 minutes. The video is an animated film with a moral value. The students are provided with a questionnaire that evaluates the understanding level, interest, vocabulary gained and feedback of the students. The students are asked to answer their interest about the 'video as an aid' before showing them the video. The rest of the questions are answered after watching the video.

The following bar graph shows the results of the survey

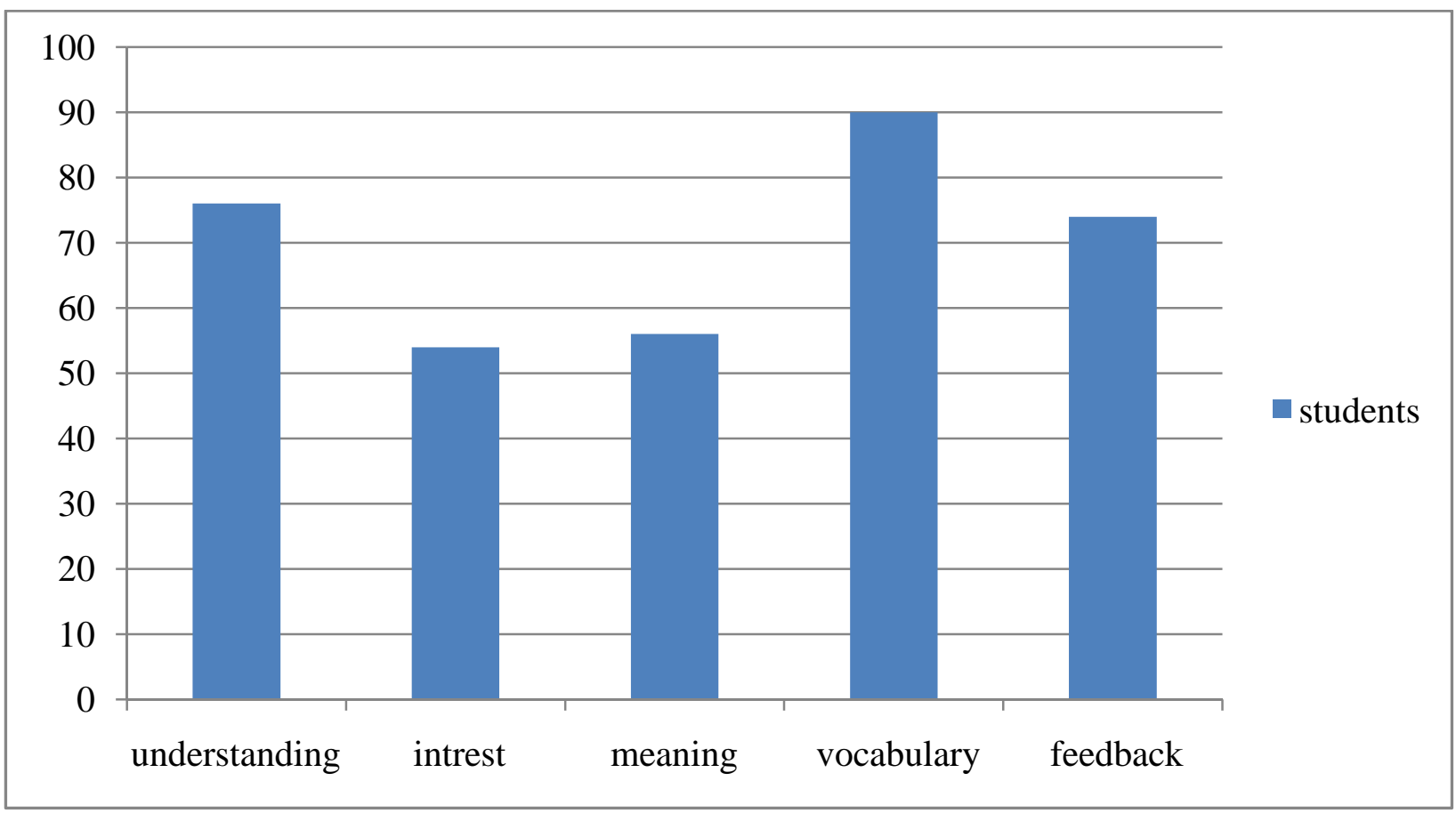

\section{Interest of students before watching the video}

Before starting the survey, the students were enquired about their personal preference regarding their study material - videos or reading. As the students have never tried watching videos as part of their curriculum, most of the students have shown interest in reading books and writing notes for studying over studies through visual aids. In Kerala, $90 \%$ of schools follow the traditional teaching methods of dictating notes and explaining it by the teachers.

\section{Understanding level}

The very first question is on children understanding the concept from the video. Whether they have understood the video or not? is a question of concern. For this, children were asked to answer about what they had understood from the video. Many of the children had answered about the moral they had understood from the video. The storyline is the main focus of many. Thus the video seems to be understandable aid for the $76 \%$ of the students. Even though they have understood the concept many of the students failed to understand the exact 
meaning of certain words. As the understanding level is more than $70 \%$ we have cross checked them by giving a match the following question. Only $56 \%$ of students are able to match it properly.

\section{Vocabulary}

Every children start studying by observing and imitating what they see and when a video is shown to them they pickup words which can grab their attention and try to use it in their daily language to show off their knowledge to others. In a way this is beneficial as at least to boast their skill and they try to ape the words according to the situation that they saw in the video. They were asked to write the new words that they have learned from the video and shockingly $90 \%$ of students have learned more than 2 words but the rest $10 \%$ of students have frankly wrote they haven't learnt any new words.

\section{Feedback}

What was their interest before watching the video have changed after watching. $75 \%$ of students have shown great interest in watching video as part of studying as it is both entertaining as well as didactic.

The following line graph shows a rapid increase in the interest after watching the video

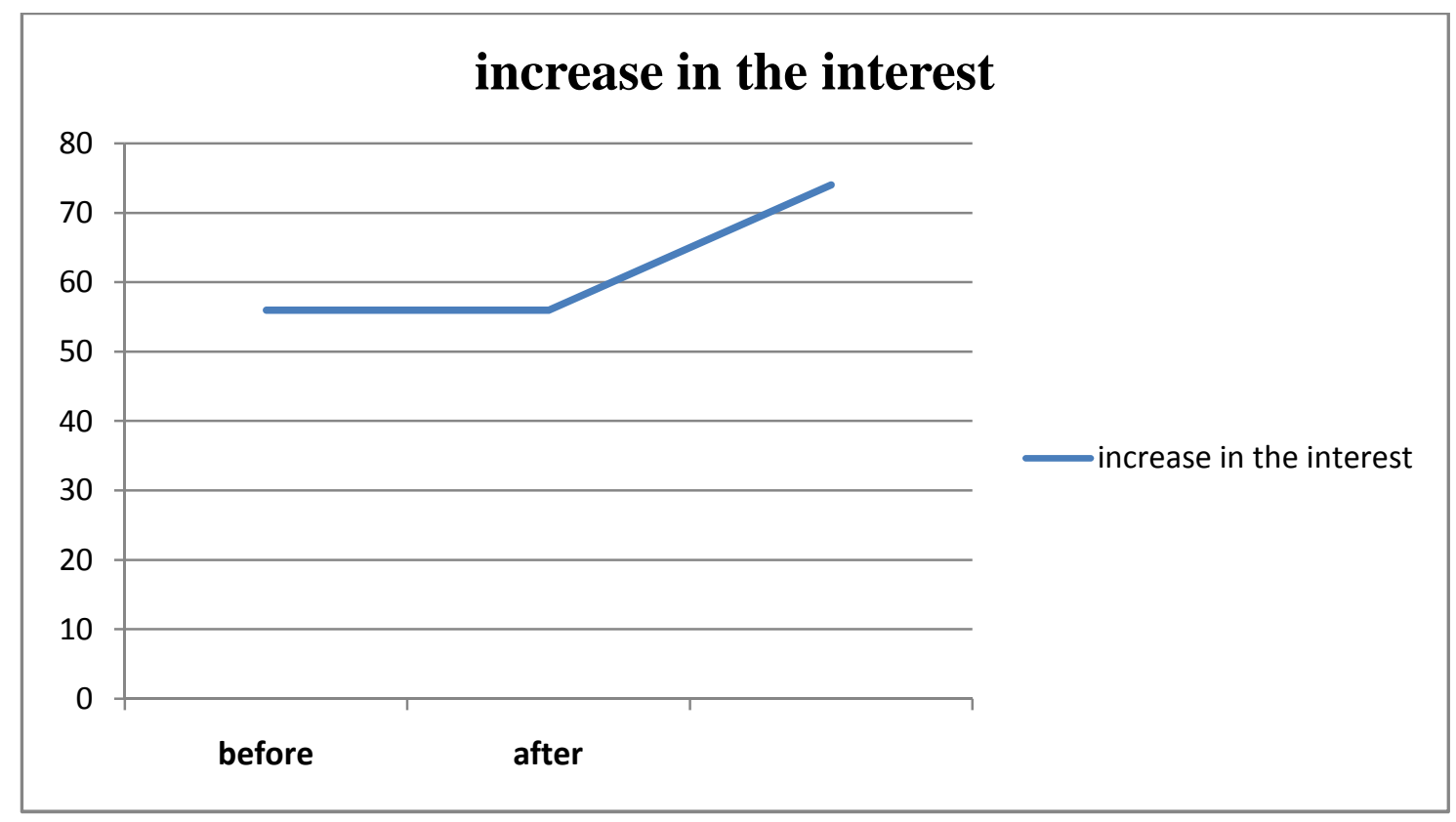

\section{Limitations}

$>$ Students are scared of teachers and reluctant to answer frankly about their interest about watching videos

$>$ Many students paid less attention as they thought that the session was a free period

$>$ Lack of technical support to analyze the pronunciation. So we couldn't analyze the improvement in pronunciation they have gained by watching the video

$>$ Lack of sufficient time as the students were having exams

$>$ The analysis of a sampling cannot make a perfect conclusion

Ethics

The consent for the survey was taken from the principal of the esteemed institutions as well as the students who have participated in the survey.

\section{Conclusion}

There is indeed a reason why digital learning or e-learning is gaining prominence in the modern scenario. There is a new mantra in e- learning, and it is called "show, don't tell". According to the survey conducted by the author and co-authors of this paper, we were able to find that visual learning is much more useful in teaching. The purpose of this survey was to find upto what extent is visual learning helping the students of the age group 8 to 10 learn much faster and efficiently than learning from books, like we always do in schools. Over the past few years, videos are being used by the teachers to teach. Or in other words, videos are supporting the teachers to 
convey their ideas properly to the students. Videos are being widely used in the classrooms for supporting teachers' curriculum and helping the students learn the material faster than ever. When the students are watching a video and learning something new, they grasp it faster than they learn it when they read a book and learn from it. More than half of the students who underwent the survey proves the above mentioned statement to be right. Research done all around the world on this very topic, on the possibilities of digital learning or e- learning to be much more profitable in case of students. Research shows that more than $94 \%$ of the teachers have effectively tried using and succeeded in using videos during the past few academic years and they have found video learning quite impressive. They say that it is much more of a help to them more than that of the traditional text-book teaching. When the teachers are teaching via the method of text-book, there are high chances that students may feel bored and there are chances of them not listening to the class. In such cases, digital learning is of help.

There are various aspects on which we have tested the students. The survey was conducted to prove that the students are able to understand the concept and meaning of what is shown to them. Videos, just like animation, impress the student than the usual style of learning via text-books. From a very young age itself, children are made to watch cartoons for making the tasks easy for parents. Let it be for keeping the child sit at one place or for making them eat food, cartoons or videos are of great help. But, little do the parents notice that their children are learning atleast a new word per day. So starting from there, children start to learn from videos. So obviously when in schools too, when they are learning through the digital media, they tend to learn much faster than when they learn through the traditional method of learning via text-book. In digital learning, there is no reading, it's only watching. Difficult or abstract concepts that are hard for the teachers to explain via any other methods of teaching, or the concepts that causes confusion among the students when the teacher explains it by the traditional method of text-book learning can be taught easily through digital learning. The attention of the students will never divert from the video through which the concept is being taught, and the whole credit for this goes to all the parents who took the aid of cartoons and videos to make their works easier. Students pay full attention to the video that they are made to watch as it is something that they love to do.

The visual demonstration given to them make them do their work faster. This is because major part of the human brain is devoted towards processing the visual information. The information that gets into a child's brain much faster than that which is taught to them through any other methods of teaching. Remembering something that is learned through a video retains in mind for a longer time rather than that which is learned through the traditional method of learning through text-books. Through videos, anyone can do self-study;when the students are shown videos, they are learning the concepts conveyed through the video by themselves. Here the role of the teacher is toexplain the parts which are difficult and also to clear the doubts that the students raise. Sometimes the teacher may explain the concept in a brief way before showing them the video so that the children will have an idea on what they are about to see. The method of digital learning helps the students to improve their vocabulary. Students learn atleast a new word through every video they watch. Children tend tolearn new things, concepts and new words not only from the educational videos that are shown by the teachers inside the class rooms. They will learn all these from movies, series and soap operas which are telecasted in televisions too.

Videos have now become a part of classroom learning. Digital learning is widely used both in online classrooms and physical classrooms. The students from a very young age group, seems to get adapted much faster to the method of digital learning. Even though digital learning is gaining prominence in this digital era, some students on one hand still prefer the old traditional method of learning via text-books. And some students on the other hand prefer some other methods of learning, like listening to audios and studying. But all these sessions of students still constitute only less than $10 \%$ of the total students who underwent the survey. This statistics itself shows how important or how efficient, learning through videos is. Prior to presenting the video, when asked, most of the students said that they preferred learning through reading books or in other words, they preferred the old, traditional method of learning through text-books. So, preceding the real survey, or before the video clip was played, we made sure to get a response from the students regarding which was their favorite mode of studying or which mode of studying did they prefer for studies. And to this question, a major portion of the students replied that they preferred the old traditional method of learning, after getting a proper response from each and every student, a 15 minutes long video was played, with audio content. It was after this video clip that we conducted the survey. Through the survey, we were able to understand how much the students were able to grasp the idea of the content through the new method of digital learning that was introduced to them. After playing the video clipping and taking the survey, as a feedback question, once more we asked the students the very same question that we asked before playing the video clip- which mode do they prefer to study? And now, most of the students affirmed that learning through watching videos was much more interesting and effective than learning by reading books. 


\section{Appendix}

Questionnaire

1. Which mode of studying do you find more interesting?

(a) Reading books

(b) Watching Videos

(c) Any other (if so mention it)

2. What is the context of the video?

3.From the video you saw match the words with their meanings
(a)Starve $\quad-$ A long walk
(b)Argue $\quad-$ Creep
(c)Sneak - Die from hunger
(d)Hike $\quad-$ Quarrel

4. Did you learn any new words from the video presented? If so mention any one or two.

5. Give us a feedback on how informative the video session was.

\section{References}

Cueto, M. D. C. H., Ramos, M. G., Garcia, M. G. O., \&Cheol., Y. S. (2017). The Use of Technologies in Second Language Learning: The Case of a Mexican University. European Scientific Journal, ESJ, 13(25), 264. doi: 10.19044/esj.2017.v13n25p264

D., S. (2019, June 3). The 6 Best Sources of Language Learning Videos on the Internet. Retrieved from https://www.fluentu.com/blog/language-learning-videos/.

Wang, Z. (2014). An Analysis on the Use of Video Materials in College English Teaching in China. International Journal of English Language Teaching, 2(1). doi: 10.5430/ijelt.v2n1p23 